\title{
Fear potentiation of the acoustic startle reflex using noises of various spectral frequencies as conditioned stimuli
}

\author{
SERGE CAMPEAU and MICHAEL DAVIS \\ Yale University School of Medicine, New Haven, Connecticut \\ and the Ribicoff Research Facilities of the Connecticut Mental Health Center \\ New Haven, Connecticut
}

\begin{abstract}
The effectiveness of noise of various intensities and frequencies in modulating the amplitude of the acoustic startle reflex was evaluated, as a preliminary test of the capacity of these noises to produce consistent and reliable fear-potentiated startle in rats. It was determined that bands of noise containing high frequencies (greater than $10 \mathrm{kHz}$ ) tend to unconditionally reduce acoustic startle responses, probably by masking the high-frequency startle-eliciting stimulus. Noise containing high frequencies produced reliable fear-potentiated startle only when its estimated unconditioned startle suppression was subtracted from the enhancement obtained after pairing it with footshocks. Noises devoid of high frequencies produced modest unconditioned startle enhancements and the most robust and reliable fear-potentiated startle when they were paired with footshocks. A nonmonotonic relationship between training shock intensity and the level of fearpotentiated startle was also exhibited when a low-frequency noise was used as a conditioned stimulus, a finding consistent with previous studies in which a visual stimulus was used. Finally, a differential Pavlovian conditioning procedure indicated that rats could readily discriminate between two different low-frequency bands of noise. The outcome of these experiments indicates that it is easier to employ low-frequency bands of noise to obtain auditory fear-potentiated startle with high-frequency startle-eliciting stimuli.
\end{abstract}

The fear-potentiated startle paradigm, in which the amplitude of the acoustic startle reflex is enhanced in the presence of a conditioned stimulus (CS) previously paired with an aversive unconditioned stimulus (US), has repeatedly been used to study Pavlovian (classical) conditioning processes (Brown, Kalish, \& Farber, 1951; cf. Davis, 1986). In most studies in which the fear-potentiated startle paradigm has been used, CSs have been either visual or compound visual-auditory stimuli. In only a few studies has fear-potentiated startle been found with the exclusive use of auditory CSs (Hitchcock \& Davis, 1987; Siegel, 1967; Swerdlow, Britton, \& Koob, 1989). Attempts at replicating auditory fear-potentiated startle in our laboratory have usually generated inconsistent results. Reliable startle potentiation in the auditory modality would allow tests of the generality of previous findings obtained with visual CSs, as well as the study of higher order conditioning phenomena, through the use of the fearpotentiated startle paradigm.

This research was supported by NIMH Grant MH-25642, MH-47840, NINCDS Grant NS-18033, Research Scientist Development Award MH00004 to Michael Davis, a grant from the Air Force Office of Scientific Research, and the State of Connecticut. We thank William A. Falls for his comments on an earlier draft of this manuscript. We are also grateful to Court Chapman, Bruel \& Kjaer representative, for spectrogram measurements. Correspondence concerning this article should be addressed to Michael Davis, Department of Psychiatry, Yale University School of Medicine, 34 Park Street, New Haven, CT 06508.
In the course of pilot work done with pure tone and white noise CSs, rats visibly demonstrated some memory of the auditory CS-shock experience in that strong "freezing"' responses (Blanchard \& Blanchard, 1969; Bolles \& Fanselow, 1980), characterized by complete cessation of movement upon auditory CS presentations, were observed. Nevertheless, in the same test session, animals displaying strong freezing responses did not show auditory CSpotentiation of the acoustic startle reflex (Campeau \& Davis, unpublished observations). It appears that intramodal interactions between the startle-eliciting stimulus and the specific, auditory CSs interfere with the expression rather than the acquisition of fear-potentiated startle.

Recent data indicate that modulation of startle amplitude by background noise is significantly modified by the spectral frequency composition of that noise (Gerrard \& Ison, 1990). Thus, at increasing intensities, low-frequency bandpass noise enhances, whereas high-frequency bandpass noise reduces, startle elicited with a high-frequency startle stimulus (Gerrard \& Ison, 1990). On the other hand, low- and high-frequency bandpass noises reduce startle amplitude elicited with a low-frequency startle stimulus. Masking of the startle stimuli by the higher intensity noises was proposed by Gerrard and Ison to explain the reduction of startle amplitudes that they obtained.

These interactions between startle-eliciting and noise stimuli suggest that a noise that produces moderate startle enhancement (i.e., low-frequency band) may act as 
a better auditory $\mathrm{CS}$ than a high-frequency noise, because the latter may mask and therefore depress the acoustic startle reflex elicited with a high-frequency startle stimulus. Thus, the goal of the following experiments was to characterize the capacity of noise of different frequencies to act as CSs in the fear-potentiated startle paradigm.

\section{EXPERIMENT 1}

In Experiment 1, we investigated the unconditioned effects of noise of different frequencies and intensities on startle amplitudes elicited by a high-frequency startle stimulus. These manipulations replicated, in part, and extended Gerrard and Ison's (1990) procedures, with both similar $(30-\mathrm{sec})$ and different $(3.7-\mathrm{sec})$ noise durations, and different noise spectral frequencies.

\section{Method}

\section{Subjects}

Experimentally naive male albino Sprague-Dawley rats weighing 350-450 $\mathrm{g}$ (Charles River Co.) were used. The rats were housed in wire cages $(17 \times 35 \times 45 \mathrm{~cm})$ in groups of 5 with water and laboratory chow continuously available, and they were maintained on a 12:12-h light:dark cycle (lights on at 7:00 a.m.). The rats were acclimated to the colony rooms for 2-3 weeks before experimental testing.

\section{Apparatus}

The test cages used to measure the amplitude of the startle response in the present and subsequent experiments were five separate stabilimeter devices, described previously (Cassella \& Davis, 1986). Briefly, each stabilimeter consisted of an $8 \times 15 \times 15 \mathrm{~cm}$ Plexiglas and wire mesh cage suspended within a $25 \times 20 \times 20 \mathrm{~cm}$ heavy steel frame. The floor of each stabilimeter was composed of four stainless steel bars $(6.0 \mathrm{~mm}$ in diameter), spaced $20 \mathrm{~mm}$ apart (center to center), through which shocks could be delivered from five Lehigh Valley shock generators (SGS-004) located outside the chamber. Current intensity was measured with a $1-\mathrm{k} \Omega$ resistor across a differential amplifier of an oscilloscope in series with a $100-\mathrm{k} \Omega$ resistor connected between adjacent floor bars in each of the cages. Current was defined as the root mean square voltage across a $1-\mathrm{k} \Omega$ resistor $(I(\mathrm{~mA})=0.707 \times 0.5 \times$ peak-to-peak voltage $)$. Within the steel frame, the cage was compressed between four springs above it and a $5 \times 5 \mathrm{~cm}$ nubber cylinder below, with an accelerometer (ENDEVCO 2217E) located between the bottom of the cage and the top of the rubber cylinder. Cage movement resulted in displacement of the accelerometer, the output of which was amplified (Endevco Model 104) and fed to a Macintosh II computer. Startle amplitude was defined as the maximum accelerometer voltage that occurred during the first $200 \mathrm{msec}$ after startle stimulus onset. The stabilimeters were housed on two shelves within a ventilated, sound-attenuating chamber $(2.5 \times 2.5 \times 2 \mathrm{~m}$; Industrial Acoustic Co.).

The startle stimuli were delivered by high-frequency Radio Shack supertweeters (range, $5-40 \mathrm{kHz}$ ) located $10 \mathrm{~cm}$ behind each stabilimeter. High-frequency startle stimuli were 50 -msec bursts of white noise, generated by a Lafayette 15011 noise generator $(0-20 \mathrm{kHz})$, with a rise-decay time of $5 \mathrm{msec}$, at variable intensities. Note that the high-frequency characteristics of the present startle stimulus are given by the speaker characteristics. Background white noise $(0-20 \mathrm{kHz})$ of $55 \mathrm{~dB}$ (SPL) was provided by a white noise generator (Grason-Stadler, Model 901B) throughout all experiments. Sound level measurements were made with a Bruel \& Kjaer (B \& K) condenser microphone (Type 4133) fitted to a B \& K Model 2235 sound level meter (A scale; random input). For spectrogram determination of the various bands of noise used, a B \& K multichannel analysis system Type 3550 was used (A scale). The noise stimuli were produced by a white-noise generator (Lafayette 15800), and bandpass filtered (Krohn-Hite, Model 3100A; roll-off, $24 \mathrm{~dB} /$ octave). The background white noise and the filtered noises were amplified and mixed (auxiliary input) by a Grason-Stadler Model $901 \mathrm{~B}$ noise generator, and delivered by a single Jamocar 70 speaker (range, $.02-20 \mathrm{kHz}$ ), located approximately $70 \mathrm{~cm}$ in front of each cage (against the IAC chamber's door).

\section{Procedure}

Matching. On the first 2 days, animals were placed in the stabilimeter cages and 5 min later presented with 30 startle stimuli at 30-sec interstimulus intervals. Intensities of 90,95 , and $105 \mathrm{~dB}$ (SPL) were used, with 10 startle stimuli at each intensity. Startle stimuli were presented in a balanced, irregular order, with the restriction that each of the three intensities had to occur in every three trial blocks. The mean startle amplitude across the $\mathbf{3 0}$ startle stimuli on the last matching day was used to assign animals into groups of 5 rats each with similar means before testing.

Testing. On the day after the last matching session, all animals were returned to the test cages and $5 \mathrm{~min}$ later presented with a total of eighty $100-\mathrm{dB}$ startle stimuli at $30-\mathrm{sec}$ interstimulus intervals: 20 initial startle stimuli, followed by 10 startle stimuli that were delivered $3.2 \mathrm{sec}$ after the onset of 3.7-sec duration noise stimuli at each of four different filtered noise intensities $(60,70,80$, or $90 \mathrm{~dB}$ ), mixed with 20 additional startle stimuli (startle stimulus alone trials). A constant 55-dB background noise was maintained throughout testing. The trial types were presented in a balanced, irregular order, with the restriction that each of the five trial types (startle stimulus alone or in the presence of one of the four filtered noise intensities) had to occur in every six trial blocks (startle stimulus alone presented twice in every block). Each of four groups of animals ( $n=10$ per group) was presented with one of four frequency bandpasses: $0-1,1-10,10-20$, and $0-20 \mathrm{kHz}$, as dialed on the bandpass filter. The resulting frequency band for each setting at a nominal intensity of $70 \mathrm{~dB}$ is presented in Figure 1.

All animals were tested on each of 2 successive days, under similar testing conditions, except that the noise duration was either 3.7 or $30 \mathrm{sec}$ on the different days. The order of testing was counterbalanced.

Statistical analysis. In all experiments in which more than one startle stimulus intensity was employed, startle amplitude was averaged across startle stimulus intensities for each trial type. The mean startle amplitude in 55-dB white noise (excluding startle responses to the initial startle stimuli), which served as a baseline for comparing the effectiveness of the experimental manipulations, was subtracted from the mean startle amplitude in the presence of the noise stimuli. This provided difference scores for each animal. Analyses of variance (ANOVAs) were performed on these difference scores, with trial type as a within-subject variable, and the various other manipulations as between-subject variables. Additional $t$ tests were conducted to evaluate significant results from the overall ANOVA, when required.

\section{Results and Discussion}

Figure 2 shows the mean difference scores in the presence of the different frequencies of noise at the intensities and durations employed. Modulation of startle amplitude was obtained with most of the frequency bands, with the lower band enhancing and the higher band reducing startle amplitudes, as the noise intensity increased. To statistically evaluate the changes from baseline startle induced by the different frequency bands, an ANOVA of 


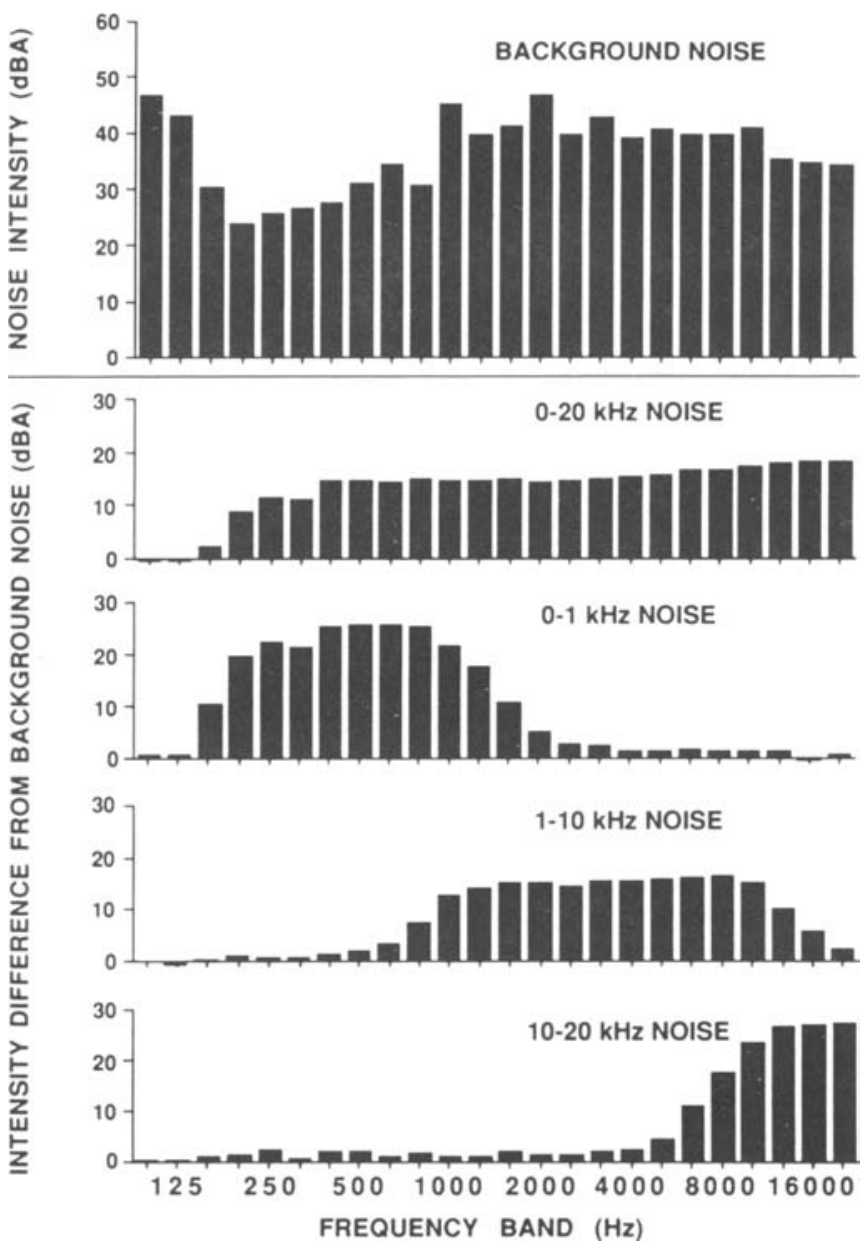

Figure 1. Frequency spectrogram, in one-third octaves, of the background noise (white, 0-20 kHz) at a nominal intensity of $55 \mathrm{~dB}(\mathrm{~A})$. NoteThe intensity at each one-third octave is lower than the complex weighted sum of all one-third octaves, indicated by the nominal intensity (total energy). Similar spectrograms of the differences from the background noise of the different bands of noise used $(0-20,0-1,1-10$, and $10-20 \mathrm{kHz}$ ) at nominal intensities of $70 \mathrm{~dB}(\mathrm{~A})$.

the mean difference scores was carried out with noise intensity $(60,70,80$, and $90 \mathrm{~dB})$ and noise duration $(3.7$ and $30 \mathrm{sec})$ as within-subject variables, and band frequency $(0-1,1-10,10-20 \mathrm{kHz})$ as a between-subject variable. The $0-$ to $20-\mathrm{kHz}$ noise was left out of this and subsequent statistical analyses, because the effects of the separate frequency components were of interest. However, the effects of the noise composed of all frequency bands $(0-20 \mathrm{kHz})$ are presented for comparisons. There was a significant effect of noise frequency $[F(2,27)=$ $10.81, p<.001]$, as well as significant interactions of intensity $\times$ frequency $[F(6,81)=7.24, p<.001]$, and intensity $\times$ duration $[F(3,81)=3.49, p<.02]$. The noise intensity $x$ duration interaction indicated that the shorter 3.7-sec noises produced less startle facilitation (or more startle reduction) at some noise intensities than did the 30-sec noises. The frequency effect and intensity $x$ frequency interaction indicated that the lower frequency bands facilitated, whereas the high-frequency band reduced, startle responses as a function of intensity.

However, individual $t$ tests on the 3.7-sec noises at each frequency and intensity indicated that only the 10- to 20 $\mathrm{kHz}$ noise at an intensity of $90 \mathrm{~dB}$ produced significant changes in startle amplitudes $[t(9)=5.00, p<.001]$. Similar analyses on the 30 -sec noises indicated that the 90-dB lowest $(0-1 \mathrm{kHz})$ and highest $(10-20 \mathrm{kHz})$ frequency bands produced significant modulation of baseline startle $[t(9)=6.17$ and 3.90 , respectively, $p$ s < $.005]$. As for white noise $(0-20 \mathrm{kHz})$, only the $90-\mathrm{dB}$, 3.7 -sec noise significantly reduced startle amplitudes $[t(9)$ $=4.63, p<.001]$.

The results of the different bands of noise cannot be attributed to different baseline startle levels between the frequency conditions, because an ANOVA of mean baseline startle amplitudes showed no significant effect of frequency $[F(2,27)=0.11]$ and no frequency $\times$ duration 


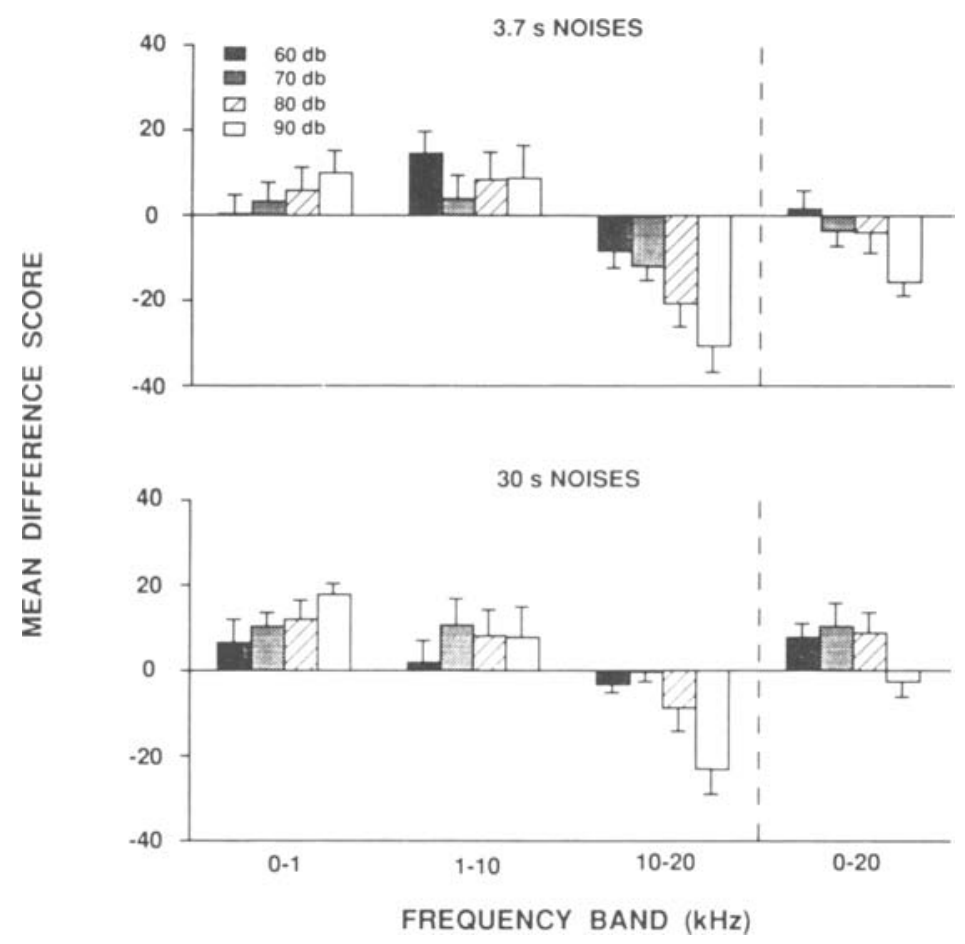

Figure 2. Mean differences $( \pm S E M)$ between startle amplitude in the presence and in the absence of the indicated frequencies of noise at various intensities. The upper panel shows the mean difference scores in the presence of 3.7-sec noises, and the lower panel shows mean differences in the presence of $30-\mathrm{sec}$ noises.

interaction $[F(2,27)=0.87]$. The mean startle baselines were $41.9,39.3,46.1,33.6,31.0$, and 37.2 for the 0 to $1-\mathrm{kHz}, 1-$ to $10-\mathrm{kHz}$, and $10-$ to $20-\mathrm{kHz}$ groups at $3.7-$ and 30 -sec noise durations, respectively.

Thus, the modulatory effects of the 3.7-sec noises were moderate and only produced significant reduction of startle at the highest frequency band. The modulatory effects of the 30-sec noise duration were similarly moderate, although significant facilitation and reduction in startle responses were obtained at the highest noise intensity for the lowest and highest frequency bands, respectively. The 30 -sec noise duration results replicate those reported by Gerrard and Ison (1990) with a startle-eliciting stimulus composed primarily of relatively high frequencies, and relatively low- $(0-1 \mathrm{kHz})$ and high-frequency $(10-$ $20 \mathrm{kHz}$ ) bands of noise. The present results extend Gerrard and Ison's findings to a shorter, 3.7-sec noise duration. The intermediate frequency $(1-10 \mathrm{kHz})$ band of noise does not produce an intensity-related modification of startle, although its effects are more similar to those of the lower, $0-$ to $1-\mathrm{kHz}$ band. The effect of white noise $(0-20 \mathrm{kHz})$ on the startle reflex appears to be best described by the summation of the effect of its component frequencies. This appears to account for the general finding of a nonmonotonic relationship between white noise intensity and startle amplitude reported in most acoustic startle studies in which white noise has been employed in conjunction with high-frequency startle stimuli (see Gerrard \& Ison, 1990).

\section{EXPERIMENT 2}

As was discussed in the introduction, it is possible that frequencies of noise producing unconditioned startle enhancement may more easily allow the expression of potentiated startle than frequency bands that may mask and thus unconditionally suppress the acoustic startle reflex. It would also be desirable to use parameters that would produce only weak unconditioned modulation of startle. Experiment 1 suggests that the unconditioned startle modulation produced by relatively short, $3.7-\mathrm{sec}$ noises are modest at an intensity of $70 \mathrm{~dB}$. This duration was also chosen to match that routinely employed to produce visual potentiated startle in our laboratory. Therefore, the goal in Experiment 2 was to evaluate the capacity of $3.7-\mathrm{sec}$, 70-dB noise of different frequency bands to produce fearpotentiated startle.

\section{Method}

Animals

One hundred experimentally naive rats were used.

\section{Procedure}

The apparatus and matching procedures were identical to those in Experiment 1. 
Training. On the day after the last matching session, the rats were placed in the stabilimeters, and 5 min later, animals in the paired condition received $10 \mathrm{CS}$-US presentations that consisted of a 3.7- $\mathrm{sec}$ noise CS coterminating with a $0.5-\mathrm{sec}, 0.6-\mathrm{mA}$ footshock US. The average intertrial interval was $5 \mathrm{~min}$ (range, 3-7 min). The same procedure was repeated the next day. One control procedure consisted of specifically unpaired presentations of the same CS and US as were presented to the paired animals. Another control procedure consisted of presenting the CS alone. Paired, unpaired, and CS alone groups were trained with the frequency bandpasses used in Experiment 1 , of $0-1,1-10,10-20$, or $0-20 \mathrm{kHz}$ at nominal intensities of $70 \mathrm{~dB} \mathrm{SPL}$ ( $n$ s of 10 for paired and unpaired groups and $n s$ of 5 for the CS alone groups).

Testing. Two days after the last training day, all animals were returned to the stabilimeters, and 5 min later, the first of 100 startle stimuli was presented at a $30-\mathrm{sec}$ interstimulus interval; there were 40 initial $95-\mathrm{dB}$ startle stimuli, followed by 10 startle stimuli at each of three different intensities $(90,95$, or $105 \mathrm{~dB})$ in the presence of the appropriate noise CS (CS and startle stimulus) and 10 in its absence (startle stimulus alone). On the CS trials, the startle stimulus was presented $3.2 \mathrm{sec}$ after the onset of the 3.7 -sec noise CS. Trial types were presented in a balanced, irregular order, with the restriction that each of the trial types had to occur in every sixtrial block.

\section{Results and Discussion}

Figure 3 shows the mean startle amplitudes and difference scores, following paired, unpaired, and CS alone training. An ANOVA of the mean startle amplitudes of the groups trained with the $0-$ to $1-\mathrm{kHz}, 1-$ to $10-\mathrm{kHz}$, and $10-$ to $20-\mathrm{kHz}$ noise bands revealed significant trial type and training effects $[F(1,66)=34.20$, and $F(2,66)=$ 10.22 , respectively, $p s<.001]$, with significant interactions of trial type $\times$ noise frequency $[F(2,66)=15.61$, $p<.001]$ and trial type $\times$ training $[F(2,66)=54.50$, $p<.001]$. Additional $t$ tests on the trial types for each band of noise showed that the $0-$ to $1-\mathrm{kHz}$ and $1-$ to $10-\mathrm{kHz}$

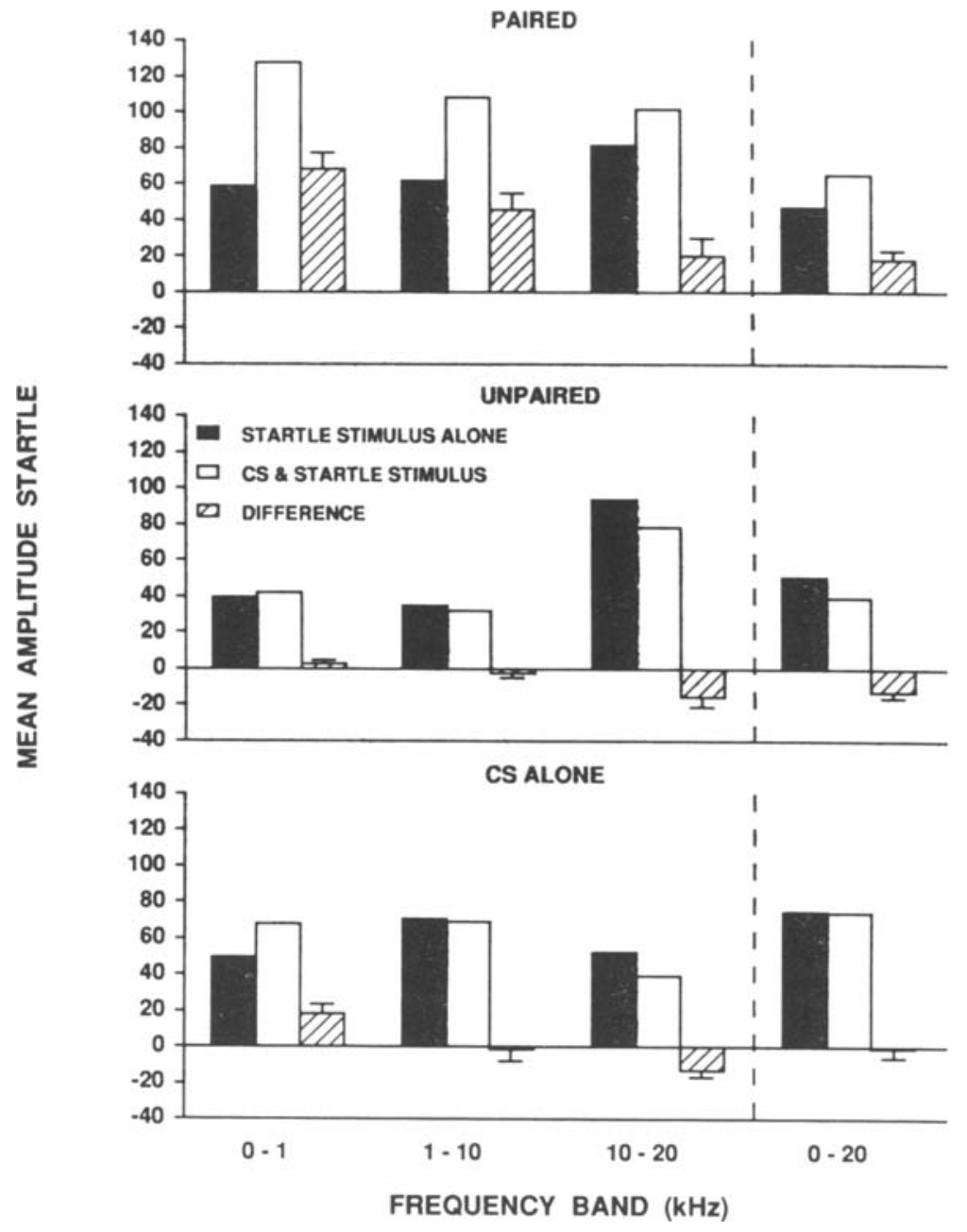

Figure 3. Mean startle amplitude in non-CS (startle stimulus alone) and CS test trials (CS and startle stimulus), and their differences ( $t S E M$ ), for paired (upper panel), specifically unpaired (middle panel), and CS alone (lower panel) groups at the indicated frequencies. 
Table 1

Corrected Difference Score Means ( \pm Standard Error)

\begin{tabular}{|c|c|c|c|c|}
\hline \multirow{3}{*}{$\begin{array}{c}\text { Noise Band } \\
\quad(\mathrm{kHz})\end{array}$} & \multicolumn{4}{|c|}{ Training Condition } \\
\hline & \multicolumn{2}{|c|}{ Paired } & \multicolumn{2}{|c|}{ Unpaired } \\
\hline & $M$ & $S E M$ & $M$ & SEM \\
\hline $0-1$ & 50.15 & 6.41 & -15.35 & 2.23 \\
\hline $1-10$ & 47.16 & 8.84 & -1.25 & 2.07 \\
\hline $10-20$ & 33.30 & 10.23 & -1.99 & 5.36 \\
\hline $0-20$ & 18.61 & 5.08 & -11.64 & 2.84 \\
\hline
\end{tabular}

bands produced significant potentiated startle ( $p s \leq .001)$, unlike the $10-$ to $20-\mathrm{kHz}$ noise. The $0-$ to $20-\mathrm{kHz}$ noise also did not produce significant startle potentiation.

These results indicate that reliable startle potentiation can be obtained with various bands of noise, provided that they are devoid of relatively high frequencies, which can apparently mask the startle stimulus, in support of our initial hypothesis.

It should be noted that the conditioning results from the paired and unpaired groups are contaminated by the unconditioned effects of the respective noise frequencies, even if these effects were expected to be modest, in view of the results from Experiment 1. A more accurate measure of learned fear would require the subtraction of each noise's unconditioned effect from its respective conditioned effect, if it is assumed that the conditioned and unconditioned effects summate. The best estimates of these unconditioned noise effects for the training and testing conditions above are provided by the CS alone groups. Thus, the mean difference score from each CS alone group was subtracted from each animal's difference score in the corresponding frequency conditions for the paired and unpaired groups, for which the means and standard errors are presented in Table 1. An ANOVA of the corrected difference scores of the $0-$ to $1-\mathrm{kHz}, 1-$ to $10-\mathrm{kHz}$, and $10-$ to $20-\mathrm{kHz}$ band groups revealed a significant training effect only $[F(1,72)=85.02, p<.001]$. NewmanKeuls post hoc comparisons of the corrected difference score means indicated that none of the unpaired groups differed from each other, none of the paired groups differed from each other, and all the paired groups were different from all the unpaired groups $(p<.05)$. Thus, the corrected difference score means of the paired groups reflected more similar levels of fear-potentiated startle across the different noise frequencies than did the uncorrected means. This outcome did not appear to generalize as much to the $0-$ to $20-\mathrm{kHz}$ band group, however (see Table 1). Overall, these results lend some support to the notion that expression, and not acquisition, of learned fear can be compromised by masking of the high-frequency startle stimulus by the higher frequency bands of noise. For white noise, however, summation of the conditioned and unconditioned effects are not sufficient to elevate startle potentiation to the levels observed with the separate bands tested.

\section{EXPERIMENT 3}

When visual conditioned stimuli are used, the magnitude of potentiated startle declines with the use of higher shock intensities (nonmonotonic effect; see Campeau, Liang, \& Davis, 1990; Davis \& Astrachan, 1978; Leaton \& Borszcz, 1985). To further evaluate the similarity of fear-potentiated startle obtained with visual and with auditory CSs, potentiated startle produced by higher training footshock intensities was investigated. It might also be possible that a nonmonotonic-like process may provide the basis for the lower, albeit nonsignificant corrected difference scores of the highest frequency band group in comparison with the lower band groups obtained in Experiment 2 . The pairing of a moderate-intensity footshock $(0.6 \mathrm{~mA})$ with a very salient CS (rats have relatively low auditory thresholds in the higher frequency spectrum; Kelly \& Masterton, 1977) may have produced such strong conditioning (Kamin, 1965) as to effectively promote the same outcome as pairing a stronger US with a less salient CS. To test this hypothesis, the noise bands observed to produce the best and worst uncorrected potentiated startle in Experiment 2 were used as CSs, and a footshock intensity lower than that used in Experiment 2 was also investigated.

Method
Animals
Sixty experimentally naive rats were used.
Procedures
The apparatus and matching procedures were identical to those
used in Experiment 1 .
Training. On the day after the last matching session, the rats
were placed in the stabilimeters, and 5 min later, they received 10
CS-US presentations of a 3.7 -sec, 70 -dB noise CS of either $0-1$
or $10-20 \mathrm{kHz}$, coterminating with a 0.5 -sec footshock US of 0.4 ,
0.8 , or $1.2 \mathrm{~mA}$ ( $n=10$ per group). The intertrial intervals were
similar to those in Experiment 2 . The same procedure was repeated
the next day.
Testing. The testing procedure was identical to that in Ex-
periment 2 .

\section{Results and Discussion}

Mean startle amplitude in the presence and absence of the $0-$ to $1-\mathrm{kHz}$ or $10-$ to $20-\mathrm{kHz}$ noise CSs paired with various footshock intensities are depicted in Figure 4, which shows that the $0-$ to $1-\mathrm{kHz}$ noise $\mathrm{CS}$ produced higher levels of potentiation, and that the lower shock intensities $(0.4,0.6$, and $0.8 \mathrm{~mA})$ also produced better potentiation than did the $1.2-\mathrm{mA}$ intensity (data for the 0.0- and 0.6-mA shock intensities were reproduced from Experiment 2 for comparisons and used in the statistical analyses). An overall ANOVA of startle amplitudes indicated significant effects of shock intensity $[F(4,80)=$ $2.70, p<.05]$ and trial type $[F(1,80)=115.20, p<$ $.001]$, as well as significant interactions of noise frequency $X$ shock intensity $[F(4,80)=5.29, p=.001]$, trial type 


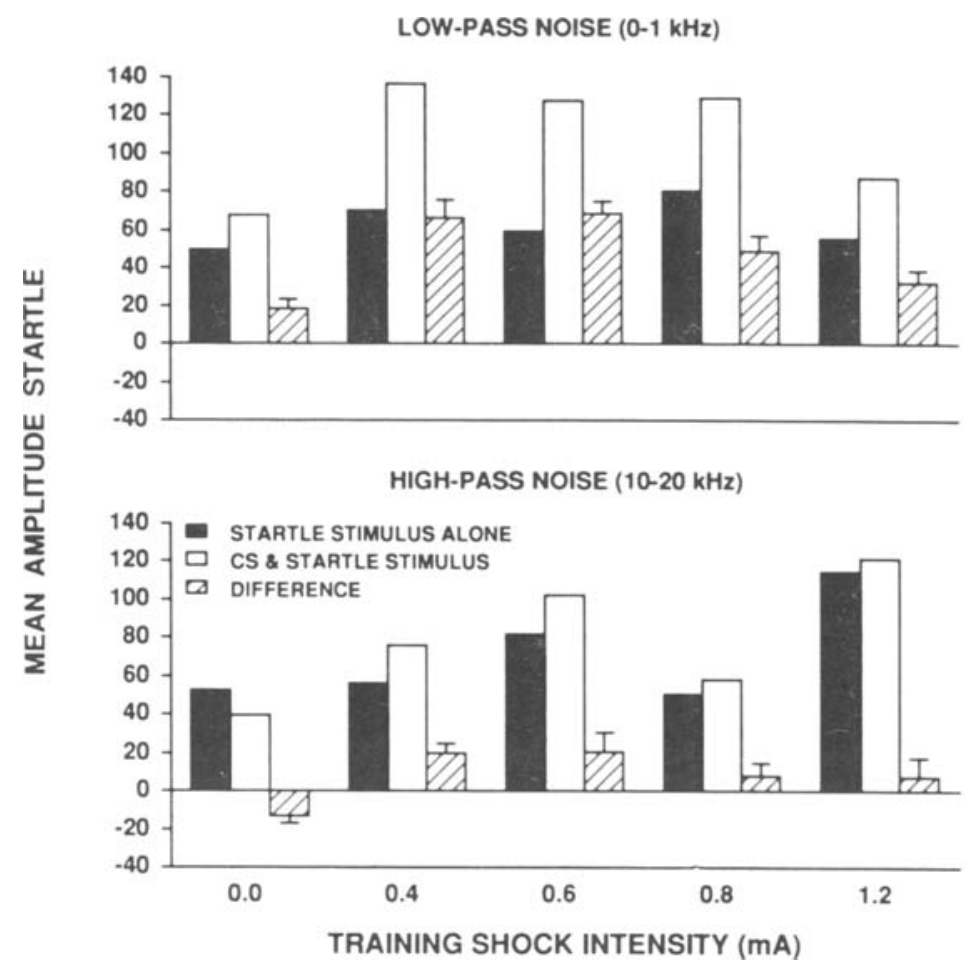

Figure 4. Mean startle amplitude in non-CS and CS test trials, and their differences $( \pm S E M)$, after training at the indicated shock intensities. The $C S$ was either a 0 - to 1-kHz (upper panel) or a 10- to 20-kHz (lower panel) noise. Results for the 0.0- and 0.6-mA groups were reproduced from Experiment 2 for comparison.

$\times$ noise frequency $[F(1,80)=55.34, p<.001]$, and trial type $\times$ shock intensity $[F(4,80)=7.78, p<.001]$. Trend analyses of the overall difference scores showed a reliable quadratic component $[F(1,80)=26.76, p<$ $.001]$, indicating a nonmonotonic relation between shock intensity and potentiated startle. Student's $t$ tests between mean startle amplitude in the presence and in the absence of the CSs showed that potentiation was obtained for all paired groups trained with the $0-$ to $1-\mathrm{kHz}$ noise $[t(9)=$ $7.58,10.69,6.04$, and 5.20 , all $p s \leq .001$, whereas only the $0.4-\mathrm{mA}$ group trained with the $10-$ to $20-\mathrm{kHz}$ noise showed significant potentiation $[t(9)=4.27, p<.005]$. To test group differences in startle potentiation, NewmanKeuls post hoc comparisons of the overall difference scores revealed that for the $0-$ to $1-\mathrm{kHz}$ noise $\mathrm{CS}$, the 0.4 and $0.6-\mathrm{mA}$ groups showed significantly higher potentiation than did the 1.2-mA group ( $p<.05$ ). For the 10to $20-\mathrm{kHz}$ noise $\mathrm{CS}$, even though $0.4 \mathrm{~mA}$ produced reliable potentiation, no significant differences between the different shock groups were obtained. Figure 4 also demonstrates a large increase in baseline startle for the group trained with $1.2-\mathrm{mA}$ shock and the $10-$ to $20-\mathrm{kHz}$ noise, which may reflect fear generalization from the highfrequency band CS to the high-frequency startle-eliciting stimulus.

Thus, a low-frequency band CS, like visual CSs, demonstrates a nonmonotonic relationship between the magnitude of fear-potentiated startle and shock intensity used in training (Campeau et al., 1990; Davis \& Astrachan,
1978; Leaton \& Borszcz, 1985). Also, it seems unlikely that the marginal potentiation obtained with the highfrequency noise CS could be attributed to a steep nonmonotonic effect due to CS and footshock intensities used in training.

\section{EXPERIMENT 4}

An alternative interpretation of the failure of the higher band of noise to generate high levels of potentiated startle could be that this noise is made perceptually louder as a result of conditioning, and therefore, that a simple subtraction of unconditioned noise effects assessed in CS alone groups could be an underestimation of this effect in paired or unpaired groups. A more direct test of sensory masking of the high-frequency startle stimulus by a high-frequency noise CS will consist of using high- and low-frequency startle-eliciting stimuli in the same test session, to reduce the frequency similarity of the startle stimulus and noise CS.

\section{Method}

Animals

Ten experimentally naive rats were used.

\section{Apparatus}

Lower frequency startle stimuli were similar to the high-frequency startle stimuli, except that the bursts of white noise were bandpass filtered through two Krohn-Hite filters (Model 3100A) in series, with the low and high cutoffs of each filter set at 0 and $5 \mathrm{kHz}$, 
respectively. This arrangement greatly attenuated the frequency components of the startle stimulus above $10 \mathrm{kHz}$, given the characteristics of the Krohn-Hite filters ( $24 \mathrm{~dB} /$ octave roll-off).

\section{Procedure}

The apparatus, matching, and training procedures were similar to those in Experiment 2.

Training. The animals received 10 pairings of a $3.7-\mathrm{sec}, 70-\mathrm{dB}$, 10 - to $20-\mathrm{kHz}$ noise, coterminating with a $0.5-\mathrm{sec}, 0.6-\mathrm{mA}$ footshock US, on each of 2 successive days

Testing. On the day following the last training day, the animals were returned to the stabilimeters, and $5 \mathrm{~min}$ later, the first of 120 startle stimuli was presented at a 30-sec interstimulus interval: there were 20 initial 95-dB high-frequency startle stimuli mixed with 20 initial 105-dB low-frequency startle stimuli, followed by 10 startle stimuli at each of two different intensities $(90$ or $95 \mathrm{~dB})$ of the highfrequency startle stimulus and 10 startle stimuli at each of two intensities $(100$ or $105 \mathrm{~dB})$ of the lower frequency startle stimulus, in the presence (CS trials) or absence (non-CS trials) of the 10to $20-\mathrm{kHz}$ noise CS. Higher intensities of the low-frequency startle stimuli were required because rats have higher thresholds for startle elicitation at low frequencies (Fleshler, 1965). On the CS trials, the appropriate startle stimulus was presented $3.2 \mathrm{sec}$ after the onset of the 3.7-sec CS. Following the 40 initial startle stimuli, the various test trials were presented in a balanced, irregular order, with the restriction that each of the startle stimuli and trial types had to occur in every eight-trial block.

\section{Results and Discussion}

Mean startle amplitude in the presence and absence of the $10-$ to $20-\mathrm{kHz}$ noise, and their differences, for the lowand high-frequency startle stimuli are presented in Figure 5, which shows that startle potentiation was only observed when startle was elicited by the lower frequency startle stimulus. This impression was supported by an ANOVA that revealed a reliable trial type $\times$ startle stimulus frequency interaction $[F(1,9)=10.99, p<.01]$, indicating that potentiation was obtained only with the

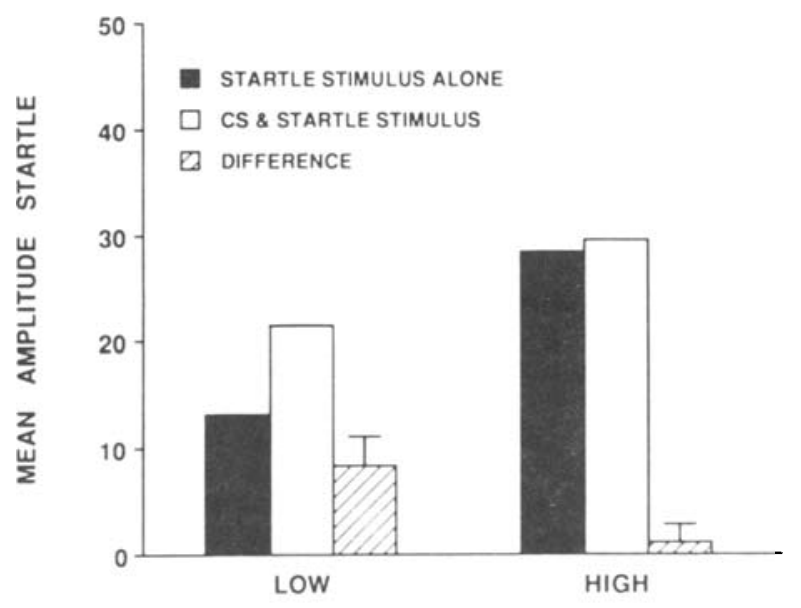

STARTLE STIMULUS FREQUENCY BAND

Figure 5. Mean startle amplitude in the presence or absence of a 10- to $20-\mathrm{kHz}$ noise $\mathrm{CS}$, and their differences $( \pm S E M)$, elicited with a low- (left) or high- (right) frequency startle stimulus. lower frequency startle stimulus. Additional ANOVAs of trial types for each startle stimulus frequency indicated that potentiation was in fact obtained only with the lowfrequency startle stimulus $[F(1,9)=8.96, p<.02]$, not with the high-frequency startle stimulus $[F(1,9)=0.39$, n.s.]. Thus, in support of the hypothesis that elicitation of startle by a high-frequency startle stimulus may be masked by the presence of a high-frequency noise CS, higher and reliable potentiated startle was obtained with the low-, but not with the high-frequency startle-eliciting stimulus.

\section{EXPERIMENT 5}

The results of Experiments 2 and 3 indicate that fearpotentiated startle can be reliably obtained with relatively broad-band, low-frequency noise CSs, without the apparent masking problems found with the higher frequency noise CSs necessitating various procedures or control groups in an attempt to obtain reliable fear-potentiated startle. However, could rats appropriately discriminate such low-frequency auditory stimuli, given their relatively higher thresholds in this region of the auditory spectrum (Kelly \& Masterton, 1977)? To address this question, a differential conditioning procedure was carried out with the two low-frequency noise CSs that produced the higher levels of startle potentiation in Experiment 2.

\section{Method}

Animals

Twenty experimentally naive rats were used.

\section{Procedure}

The apparatus and matching procedures were identical to those in Experiment 1.

Training. On the day after the last matching session, the rats were placed in the stabilimeters, and 5 min later, they received the first of five CS-US pairings (CS+), or 15 presentations of the alternate CS by itself (CS-). The CS durations were $3.7 \mathrm{sec}$, at an intensity of $70 \mathrm{~dB}$ (SPL) and at frequency bandpasses of either 0-1 or $1-10 \mathrm{kHz}$. For half the subjects $(n=10)$, the CS+ was $0-1 \mathrm{kHz}$ and the CS- was $1-10 \mathrm{kHz}$. The noise frequencies for the CS+ and $\mathrm{CS}-$ were reversed for the other animals. The CS+ coterminated with a $0.5-\mathrm{sec}, 0.4-\mathrm{mA}$ footshock US. The CS+ and CSwere randomly distributed throughout the training session, with an average intertrial interval of $3 \mathrm{~min}$ (1.5-4.5 $\mathrm{min}$ ). The same procedure was repeated for the next 4 successive days, for a total of $25 \mathrm{CS}+$ and $75 \mathrm{CS}-$ presentations.

Testing. Two days after the last training day, all animals were returned to the stabilimeters, and $5 \mathrm{~min}$ later, the first of 75 startle stimuli was presented at a $30-\mathrm{sec}$ intertrial interval; there were 10 initial startle stimuli at each of three different intensities $(90,95$, and $105 \mathrm{~dB}$ ), followed by 5 startle stimuli at each of three intensities in the presence of the paired CS (CS+ trial), in the presence of the nonreinforced CS (CS- trial), or in the absence of the noise CSs (non-CS trial). On the CS trials, the startle stimulus was presented $3.2 \mathrm{sec}$ after the onset of the 3.7-sec auditory CS. Startle stimuli were presented in a balanced, irregular order, with the restriction that each of the initial three trial types had to occur in every three-trial block (first 30 startle stimuli), and each of the nine trial types, in every block of nine trials (last $\mathbf{4 5}$ startle stimuli). 


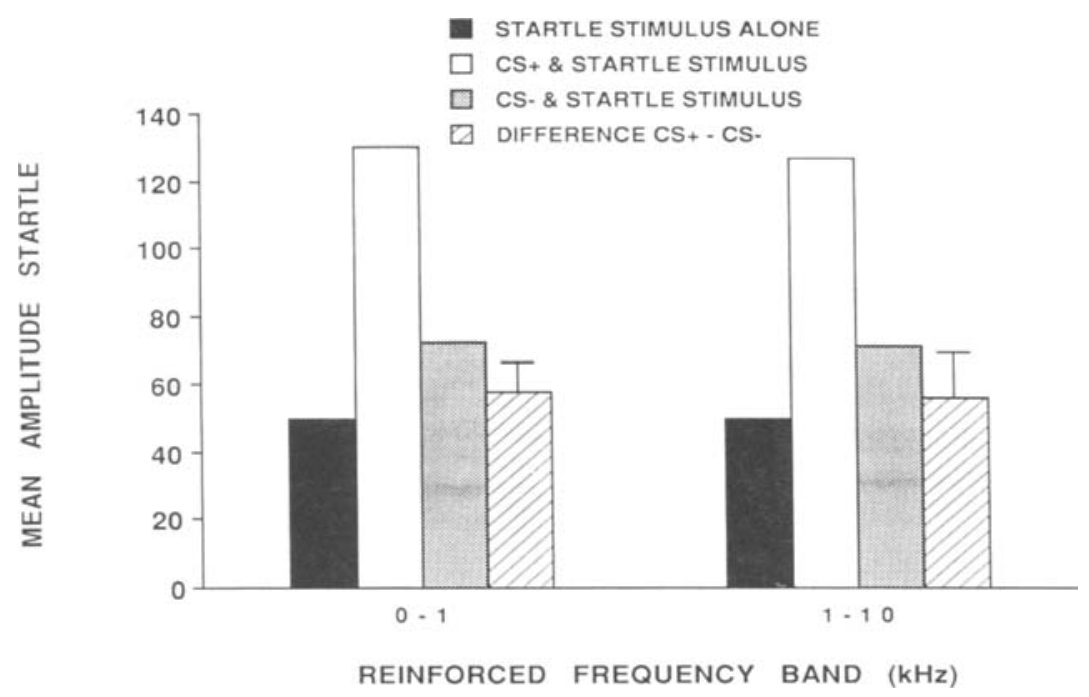

Figure 6. Mean startle amplitude in non-CS and CS (CS+ and CS-) test trials, and the mean differences between the CS+ and CS- trials $( \pm S E M)$. Animals were presented with either the $0-$ to $1-\mathrm{kHz}$ (left) or the $1-$ to $10-\mathrm{kHz}$ (right) noise as the reinforced CS, with the alternate frequency bandpass noise nonreinforced.

\section{Results and Discussion}

Figure 6 shows the mean startle amplitude and difference scores, obtained during the auditory discrimination test, with the $0-$ to $1-\mathrm{kHz}$ or $1-$ to $10-\mathrm{kHz}$ noise as the reinforced CS. An ANOVA with trial type (CS+, CS-, and non-CS trials) as a within-subject variable and reinforced noise frequency as a between-subject variable revealed a significant effect of trial type $[F(2,36)=133.61$, $p<.001]$. Importantly, no effect of frequency as the reinforced CS or interaction was detected, suggesting that each noise frequency served well as CS + or CS-. Subsequent $t$ tests revealed that the CS + and $C S-$ trial means were significantly different from the non-CS trial mean $[t(19)=13.59$ and 5.77, respectively, $p \mathrm{~s}<.001]$, and that reliably higher potentiation was obtained on CS+ than on CS - trials $[t(19)=11.98, p<.001]$. Discrimination between the two low-frequency noises was therefore demonstrated, although significant startle enhancement was also observed on the CS- trials.

\section{GENERAL DISCUSSION}

The purpose of the present experiments was to identify the characteristics of auditory stimuli that would, when the stimuli were paired with footshock, reliably enhance the startle reflex elicited by high-frequency startle stimuli. Prior work (Gerrard \& Ison, 1990) indicating that low-frequency bandpass noise enhances and highfrequency bandpass noise reduces startle elicited with a high-frequency startle stimulus suggested that lowfrequency bands may act as better auditory CSs than highfrequency noise, because the latter may mask and therefore depress high-frequency elicited startle.

In agreement with this hypothesis, the lower frequency bands tested were found to produce substantial and reli- able startle potentiation following pairings with footshocks (Experiment 2). The lowest frequency band was also the one observed to unconditionally and reliably enhance starthe in Experiment 1, as reported in the original work of Gerrard and Ison (1990). The $10-$ to $20-\mathrm{kHz}$ band of noise also produced reliable potentiated startle expression, but only after the estimated unconditioned effects were subtracted from the conditioned results (corrected data). This indicates that conditioning-induced startle enhancement can summate with the reduced startle levels unconditionally generated by high-frequency noises. However, conditioned and unconditioned summation cannot entirely explain the failure of the corrected 0 - to $20-\mathrm{kHz}$ noise to produce reliable startle potentiation, relative to the other bands of noise. It may be difficult to determine the net interaction between the unconditioned and conditioned effects of the 0- to 20-kHz noise, given its wide component frequencies. Because of this outcome, the use of control groups for the sole purpose of establishing and subtracting unconditioned from conditioned effects may not be adequate, given the mixed results that may occur.

Masking of the high-frequency startle stimulus by highfrequency bands was suggested by the outcome of Experiment 4 , in which a manipulation that directly reduced the spectral similarity between the noise CS and the startle stimulus yielded reliable fear-potentiated startle when the CS was a $10-$ to $20-\mathrm{kHz}$ noise CS. Masking probably also accounted for the only reliable suppression of startle obtained with the most intense and higher frequency bands $(0-20$ and $10-20 \mathrm{kHz})$ of noise in Experiment 1. These results are consistent with reports that the effectiveness of sensory masking in humans is largely determined by the spectral similarity of the masking and the signal stimuli (Scharf \& Buus, 1986; Scharf \& Houtsma, 1986). Although the absolute magnitude of potentiation obtained 
in Experiment 4 with the lower frequency startle stimulus was modest, it was significantly higher than the potentiation obtained when startle was elicited by the highfrequency stimulus in the same test session. It has been suggested that rats may startle, in part, in response to the cochlear high-frequency distortion products of intense, low-frequency startle stimuli (Parham \& Willot, 1988; $\mathrm{Wu}, 1987)$. Because these high-frequency distortions would also be masked by the high-frequency CS, lowfrequency startle stimuli may only be marginally more effective than high-frequency stimuli. Thus, even if significant potentiated startle can be obtained with lowfrequency startle stimuli and high-frequency noise CSs, it would be easier to specifically use high-frequency startle-eliciting stimuli in conjunction with lower frequency noise CSs.

The differential auditory conditioning results of Experiment 5 showed that the two low-frequency noises, which produced the highest levels of startle potentiation, were readily discriminable. Each of these noise bands was equally effective in serving as reinforced or nonreinforced CSs. Nonreinforced noise presentations, when mixed with reinforced presentations of the alternate $\mathrm{CS}$, also produced significant startle potentiation, in comparison with the startle stimulus alone trials. Using pure tones, Siegel (1967) demonstrated that sharp frequency generalization gradient decrements can be obtained by simple conditioning. Thus, in view of Siegel's results, nonreinforced presentation of the CS- may not have been necessary to produce the significant difference in potentiation between the CS+ and $\mathrm{CS}-$ trials. We are currently investigating this question by looking at the generalization gradients obtained with and without explicit differential training with narrower frequency bandpass noises.

Earlier problems in obtaining consistent fear-potentiated startle with white noise CSs were probably due to the unconditioned effects of its high-frequency components in relation to the general use of high-frequency startleeliciting stimuli. However, the present results do not appear to offer a satisfactory explanation of the failures to obtain significant potentiated startle with low-frequency pure tones. Irrespective of these limitations, noises of relatively low frequencies reliably produce fear-potentiated startle, and the outcome of Experiment 3, demonstrating a nonmonotonic relationship between auditory fearpotentiated startle and shock intensity, suggests that at least some of the results reported with visual CSs generalize to the auditory modality. The availability of reliable potentiated startle in the visual and auditory modalities now makes higher order conditioning phenomena amenable to study with the fear-potentiated startle paradigm.

\section{REFERENCES}

Blanchard, R. J., Blanchard, D. C. (1969). Crouching as an index of fear. Joumal of Comparative \& Physiological Psychology, 67, 370-375.

Bolles, R. C., FANSElow, M. S. (1980). A perceptual-defensiverecuperative model of fear and pain. Behavioral \& Brain Sciences, 3, 291-323.

Brown, J. S., Kalish, H. I., \& FArber, I. E. (1951). Conditioned fear as revealed by magnitude of startle response to an auditory stimulus. Journal of Experimental Psychology, 41, 317-328.

Campeau, S., Liang, K. C., \& Davis, M. (1990). Long-term retention of fear-potentiated startle following a short training session. $A n$ imal Learning \& Behavior, 18, 462-468.

Cassella, J. V., DAvis, M. (1986). The design and calibration of a startle measurement system. Physiology \& Behavior, 36, 377-383.

DAvis, M. (1986). Pharmacological and anatomical analysis of fear conditioning using the fear-potentiated startle paradigm. Behavioral Neuroscience, 100, 814-824.

Davis, M., Astrachan, D. I. (1978). Conditioned fear and startle magnitude: Effects of different footshock or backshock intensities used in training. Joumal of Experimental Psychology: Animal Behavior Processes, 4, 95-103.

Fleshler, M. (1965). Adequate acoustic stimuli for startle reaction in the rat. Joumal of Comparative \& Physiological Psychology, 60, 200-207.

GERRARD, R. L., \& IsON, J. R. (1990). Spectral frequency and the modulation of the acoustic startle reflex by background noise. Joumal of $E x$ perimental Psychology: Animal Behavior Processes, 16, 106-112.

Hrтснсоск, J. M., \& DAvIS, M. (1987). Fear-potentiated startle using an auditory conditioned stimulus: Effect of lesions of the amygdala. Physiology \& Behavior, 39, 403-408.

KAMIN, L. J. (1965). Temporal and intensity characteristics of the conditioned stimulus. In W. F. Prokasy (Ed.), Classical conditioning: $A$ symposium (pp. 118-147). New York: Appleton.

KELLY, J. B., \& MASTERTON, B. (1977). Auditory sensitivity of the albino rat. Journal of Comparative \& Physiological Psychology, 91, 930-936.

Leaton, R. N., \& Borszcz, G. S. (1985). Potentiated startle: Its relation to freezing and shock intensity in rats. Journal of Experimental Psychology: Animal Behavior Processes, 11, 421-428.

PARHAM, K., \& WiLlot, J. F. (1988). Acoustic startle response in young and aging $\mathrm{C} 57 \mathrm{BL} / 6 \mathrm{~J}$ and $\mathrm{CBA} / \mathrm{J}$ mice. Behavioral Neuroscience, 102, 881-886.

SCHARF, B., \& BuUs, S. (1986). Audition I: Stimulus, physiology, thresholds. In K. R. Boff, L. Kauffman, \& J. P. Thomas (Eds.), Handbook of perception and human performance (Vol. 1, pp. 14-1-1471). New York: Wiley.

Scharf, B., \& Houtsma, A. J. M. (1986). Audition II: Loudness, pitch, localization, aural distortion, pathology. In K. R. Boff, L. Kauffman, \& J. P. Thomas (Eds.), Handbook of perception and human performance (Vol. 1, pp. 15-1-15-60). New York: Wiley.

SIEGEL, A. (1967). Stimulus generalization of a classically conditioned response along a temporal dimension. Joumal of Comparative \& Physiological Psychology, 64, 461-466.

Swerdlow, N. R., Britton, K. T., Koob, G. F. (1989). Potentiation of acoustic startle by corticotropin-releasing factor (CRF) and by fear are both reversed by alpha-helical CRF (9-41). Neuropsychopharmacology, 2, 285-292.

WU, M.-F. (1987). Effects of prestimuli, background noise, and noise offset on the acoustic pinna reflex: The relationships between EMG and neural responses in the inferior colliculus of spinally transected rats (Doctoral dissertation, University of Rochester). Dissertation $A b$ stracts International, 48, 1839B. 